\title{
OBJETOS VIRTUAIS DE APRENDIZAGEM PARA A EDUCAÇÃO DE JOVENS E ADULTOS DISPONÍVEIS NO BANCO INTERNACIONAL DE OBJETOS EDUCACIONAIS COM FOCO EM MEIO AMBIENTE
}

\author{
Felícia Maria Fernandes Oliveira, Professora da rede estadual de ensino da Paraíba. \\ Edilson Leite da Silva, UFCG
}

\begin{abstract}
RESUMO
A sociedade atual destaca-se como tecnológica e informatizada, estando em constante transformação. A Educação de Jovens e Adultos (EJA) é uma modalidade de ensino voltada para pessoas que não tiveram acesso ao ensino regular na idade apropriada. Objetivou-se com o trabalho apresentar os objetos virtuais de aprendizagem disponíveis no Banco Internacional de Objetos Educacionais (BIOE), no ensino de Química na EJA, com enfoque no tema transversal meio ambiente. Trata-se de uma pesquisa bibliográfica, descritiva, quantitativa. Os resultados demostram uma vasta quantidade de objetos virtuais de aprendizagem que podem ser utilizados em sala de aula. Sendo que na modalidade de ensino EJA estão disponíveis 312 objetos. A presente pesquisa contribui para que professores e alunos tomem conhecimentos dos OVAs disponíveis no BIOE e possam utilizá-los como auxilio no processo ensino aprendizagem nas aulas de Ciências, Química, geografia e Biologia na Educação de Jovens e Adultos com foco no tema meio ambiente.
\end{abstract}

PALAVRAS-CHAVE: Ensino; Tecnologia; natureza.

\author{
OBJETOS VIRTUALES DE APRENDIZAJE PARA LA EDUCACIÓN DE \\ JÓVENES Y ADULTOS DISPONIBLES EN EL BANCO INTERNACIONAL DE \\ OBJETOS EDUCACIONALES CON FOCO EN MEDIO AMBIENTE
}

\section{RESUMEN}

La sociedad actual se destaca como tecnológica e informatizada, estando en constante transformación. La Educación de Jóvenes y Adultos (EJA) es una modalidad de enseñanza dirigida a las personas que no han tenido acceso a la enseñanza regular en la edad apropiada. Se objetivó con el trabajo presentar los objetos virtuales de aprendizaje disponibles en el Banco Internacional de Objetos Educativos (BIOE), en la enseñanza de Química en la EJA, con enfoque en el tema transversal medio ambiente. Se trata de una investigación bibliográfica, descriptiva y cuantitativa. Los resultados demuestran una gran cantidad de objetos virtuales de aprendizaje que se pueden utilizar en el aula. Siendo que en la modalidad de enseñanza EJA están disponibles 312 objetos. La presente investigación contribuye a que profesores y alumnos tomen conocimiento de los OVAs disponibles en el BIOE y puedan utilizarlos como auxilio en el proceso de enseñanza y aprendizaje en las clases de Ciencias, Química, Geografía y Biología en la Educación de Jóvenes y Adultos con foco en el tema medio ambiente.

PALABRAS CLAVE: Enseñanza; Tecnología; Naturaleza. 


\section{INTRODUÇÃO}

Amparada por lei, a Educação de Jovens e Adultos (EJA) é uma modalidade de ensino voltada para pessoas que não tiveram acesso, por algum motivo, ao ensino regular na idade apropriada. Sendo uma modalidade da Educação Básica dividida em duas etapas Ensino Fundamental e Médio, dando ênfase também ao ensino profissionalizante.

$\mathrm{Na}$ atualidade, a inclusão dos excluídos por longos anos do direito à educação de qualidade na EJA ainda apresenta vários desafios a serem superados, que envolvem as características de cada aluno, seus interesses, habilidades, condições de vida e trabalho. Frente a essa realidade, o professor sentir-se desafiado a inovar em sala de aula.

As Novas Tecnologias da Informação e Comunicação (NTIC) dentre elas os Objetos Virtuais de Aprendizagem (OVAs) apoiados em fundamentos sólidos da educação e com metodologias que permitam a utilização em sala de aula podem trazer diversos benefícios no processo de ensino aprendizagem, principalmente na EJA. Oliveira (2015, p.5) elucida que "as tecnologias modificam o modo de pensar, de agir e de se comunicar como o mundo [...]"

Neste contexto Objetivou-se com o trabalho apresentar os objetos virtuais de aprendizagem disponíveis no Banco Internacional de Objetos Educacionais (BIOE), no ensino de Química na EJA, com enfoque no tema transversal meio ambiente.

\section{REFERÊNCIAL TEÓRICO}

A sociedade atual destaca-se como tecnológica e informatizada, estando em constante transformação. Diante desta frenética evolução tecnologia o professor necessita está conectado com essa nova geração que vem crescendo desde a revolução industrial.

A Química é uma ciência tecnológica. Pesquisas laboratoriais e a produção industrial proporcionam o aumento da expectativa de vida da humanidade, sendo assim denominada uma ciência associada à vida. Estudos demonstram que na esfera educacional esta ciência prioriza a memorização de cálculos, regras, fórmulas e conceitos (OLIVEIRA, 2015). O que revela uma grande dificuldade em absolver conceitos químicos por parte dos alunos, motivados pela falta de conexão dos conteúdos científicos com o cotidiano e a resistência ao uso dos recursos tecnológicos por parte de muitos professores, em especial na educação de jovens e adultos. Diante dessa problemática: 
Espera-se que os professores consigam articular saberes científicos, pedagógicos e tecnológicos para o desenvolvimento de uma prática inovadora, que conduza seus alunos a conhecer, criticar, analisar, refletir, compartilhar e atuar em grupo. No entanto, fazer isso não é tarefa fácil, principalmente quando a formação inicial e continuada, por vezes, sequer apontam indícios de como essa prática pode ser realizada (SOUZA, 2015, p. 27).

Educar jovens e adultos não é apenas ensinar a ler e escrever, nem tão pouco se preocupar apenas em reduzir números e índices de analfabetismo. É oferecer uma educação igualitária, onde o indivíduo torne-se cidadão crítico instruído e pronto para o mercado de trabalho. O uso das tecnologias em especial os computadores é indispensável nesse processo.

A EJA segundo o modelo andragogia da ênfase a participação do aluno no processo de ensino aprendizagem em sala de aula, ao invés de limitar-se somente a transmissão do conteúdo e ao cumprimento do currículo (RONDÔNIA, 2013). Priorizando uma educação significativa, onde o aluno entenda o porquê de aprender determinados conteúdos. Nesse sentido o professor é um mediador do conhecimento, garantindo ao aluno um ensino significativo. Elucidando que:

A EJA tornou-se mais que um direito: é a chave para o século XXI, é tanto consequência do exercício da cidadania como condição para uma plena participação na sociedade. Além do mais, é um poderoso argumento a favor do desenvolvimento sustentável, da democracia, da justiça, da igualdade entre sexos, do desenvolvimento socioeconômico e científico, além de um requisito fundamental para a construção de um mundo onde a violência cede lugar ao diálogo e à cultura de paz baseada na justiça. (SOARES, 2002, p. 73)

A EJA propõe o resgate dos valores éticos, estéticos, democráticos e humanistas (FREITAS, 2009). Conduzindo o educando a repensar e atuar de forma crítica frente à resolução de problemas de ordem ambiental, social, político e cultural, problemas esses que devem ser discutidos no ambiente escolar contribuindo assim para formação do cidadão.

A modalidade de ensino Educação de Jovens e Adultos e as demais modalidades por meio dos Parâmetros Curriculares Nacionais (PCN) propõe que a educação ambiental seja trabalhada como um tema transversal e de forma interdisciplinar. Segundo a Lei 9.795/99, artigo $2^{\circ}$ de 1999 a Política Nacional da Educação Ambiental destaca que, Brasil (1999, p.01): “A educação ambiental é uma componente permanente da educação nacional, devendo 
estar presente, de forma articulada, em todos os níveis e modalidades do processo educativo, em caráter formal e não formal”.

Assim a Educação Ambiental contribui para a formação da cidadania ecológica. Na EJA trabalhar a Educação Ambiental contribui para a formação de cidadãos conscientes e comprometidos como o meio ambiente onde vivem, aptos para atuar em prol do bem estar da sociedade.

Nas últimas décadas vários estudiosos demonstram preocupação com a educação ambiental. Preocupação essa oriunda do desrespeito à natureza, que ocasiona desmatamentos, lixões a céu aberto, rios poluídos, além da extinção de espécies animais e vegetais. Neste contexto, deve-se promover o desenvolvimento de uma educação ambiental.

Os objetos virtuais de aprendizagem objetivam potencializar a aquisição do conhecimento, dispõem da capacidade de simular situações, animar fenômenos, podem ser utilizados em inúmeros ambientes, e apresentam conteúdos digitais que podem dar suporte no processo educacional. Um objeto virtual de aprendizagem:

É um recurso digital reutilizável que auxilia na aprendizagem de algum conceito e, ao mesmo tempo, estimula o desenvolvimento de capacidades pessoais, como por exemplo, imaginação e criatividade. Dessa forma, um objeto virtual de aprendizagem pode tanto contemplar um único conceito quanto englobar todo o corpo de uma teoria. Pode ainda compor um percurso didático, envolvendo um conjunto de atividades, focalizando apenas determinado aspecto do conteúdo envolvido, ou formando, com exclusividade, a metodologia adotada para determinado trabalho (SPINELLI, 2007, p. 7).

São muitos os repositórios que disponibilizam os OVAs e podem ser acessados gratuitamente. O BIOE não é o único repositório onde se encontra objetos virtuais de aprendizagem, o MEC também disponibiliza o portal do professor podendo ser acessado pelo link http://portaldoprofessor.mec.gov.br e RIVED endereço, http://rived.mec.gov.br/, existindo também outros repositórios desenvolvidos por instituições privadas.

No Brasil a história da Educação de Jovens e Adultos é constituída, em sua maioria por pessoas que não obtiveram sucessos na idade apropriada na escola. No processo educativo o ensino na EJA deve contribuir para que não haja evasões no âmbito de escolarização dos jovens e adultos e representar uma contribuição para o resgate da cidadania e dignidade do discente. Aliado a esse processo estão os objetos virtuais de aprendizagem que constituem-se como um maneira de tonar as aulas mais atrativas e dinâmicas. 


\section{METODOLOGIA}

A presente pesquisa foi desenvolvida com o objetivo de expor a professores e alunos os objetos de aprendizagem para ensino de Química na Educação de Jovens e Adultos - EJA disponíveis no repositório Banco Internacional de Objetos Educacionais (BIOE), que trabalham o tema meio ambiente e educação ambiental.

O procedimento metodológico iniciou-se com a pesquisa bibliográfica em documentos sobre a temática objetos virtuais de aprendizagem para o ensino de química na EJA. Prodanov e Freitas (2013, p. 54) destacam que a pesquisa bibliográfica tem por "objetivo de colocar o pesquisador em contato direto com todo material já escrito sobre o assunto da pesquisa."

Em seguida embasados na literatura optou-se por realizar uma pesquisa de natureza quantitativa, a qual coleta e apresenta as quantidades de objetos de aprendizagem disponíveis para a Educação de Jovens e Adultos no BIOE. Destacando que:

A pesquisa quantitativa recorre à linguagem matemática para descrever as causas de um fenômeno, as relações entre variáveis, etc. A utilização conjunta da pesquisa qualitativa e quantitativa permite recolher mais informações do que se poderia conseguir isoladamente (FONSECA, 2002, p. 20).

Realizou-se também a pesquisa de forma descritiva, no sentido de mostrar detalhadamente como estão organizados os OVAs que abordam a temática disponíveis e organizados no BIOE. Segundo Prodanov e Freitas (2013 p. 52) a pesquisa descritiva “observa, registra, analisa e ordena dados, sem manipulá-los, isto é, sem interferência do pesquisador."

O tratamento dos dados é apresentado em forma de figuras e quadros para facilitar a análise dos resultados, demonstrando quantitativamente os objetos de aprendizagem ofertados por cada categoria de subdivisão, retratando informações importantes sobre o funcionamento deste repositório, para que alunos e professores possam acessar aos seus objetos de aprendizagem.

\section{RESULTADOS}

O repositório Banco Internacional de Objetos Educacionais (BIOE) esta dividido por áreas do conhecimento e modalidades de ensino: Educação Infantil, Ensino Fundamental subdividido em séries iniciais e séries finais, Ensino Médio, Educação Profissional, Educação Superior e Modalidades de Ensino, esta subdividida em Educação de Jovens e Adultos (EJA) 
e Educação Escolar Indígena como mostrado na figura 1, o que atende a Lei de Diretrizes e Bases (LDB).

Figura 1- Níveis e modalidades de Ensino Disponíveis no BIOE.

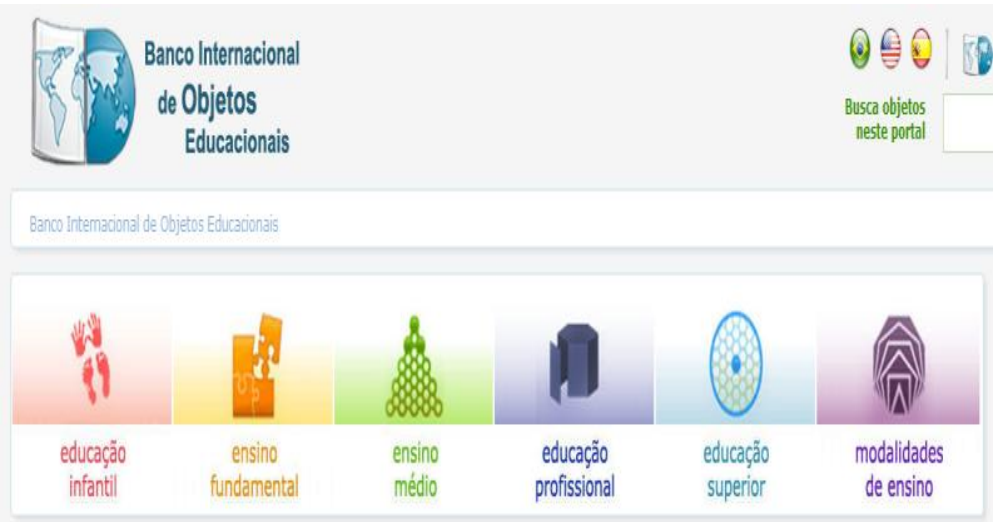

Fonte: BIOE. Acesso em: 06 de agosto de 2016.

O BIOE, é de acesso gratuito, organizado por nível de ensino, disciplinas e em sequência por categorias dos objetos, podendo ser acessado através do endereço eletrônico http://objetoseducacionais2.mec.gov.br/. Com 174 objetos sendo avaliados ou aguardando autorização dos autores para serem publicados e 19.842 objetos já publicados. No BIOE os objetos estão subdividido em 08 categorias, como mostrado na fígura 2, sendo estas: Animação/Simulação; Áudio; Experimento Prático; Hipertexto; Imagem; Mapa; Software Educacional e Vídeo.

Figura 2 - Categorias dos Objetos de Aprendizagem.

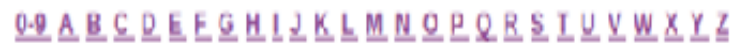

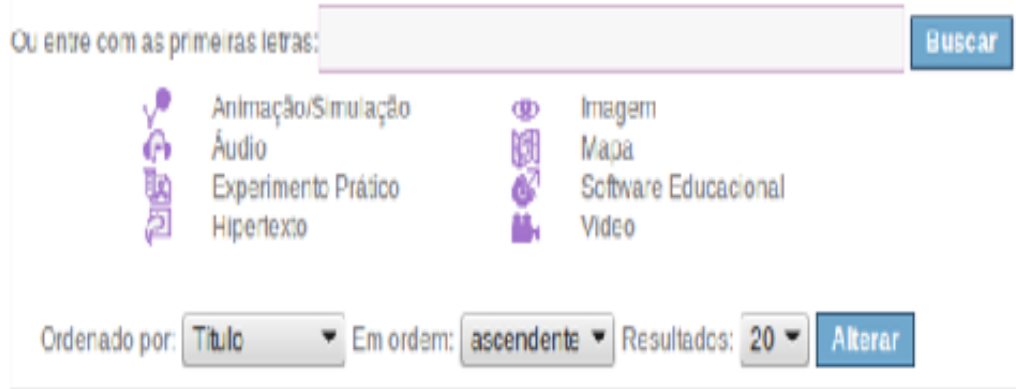

Fonte: BIOE. Acesso em: 13 de novembro de 2016.

As modalidades de ensino podem ser acessadas pelo link http://objetoseducacionais2.mec.gov.br/handle/mec/758/browse?type=title\&s=d ou clicando diretamente na imagem modalidade de ensino. Contendo um total de objetos como mostrado 
na figura 3, de 327, está dividida em educação de jovens e adultos com 312 objetos e educação indígena com 15 objetos.

Figura 5. Modalidade de Ensino Disponíveis no BIOE.

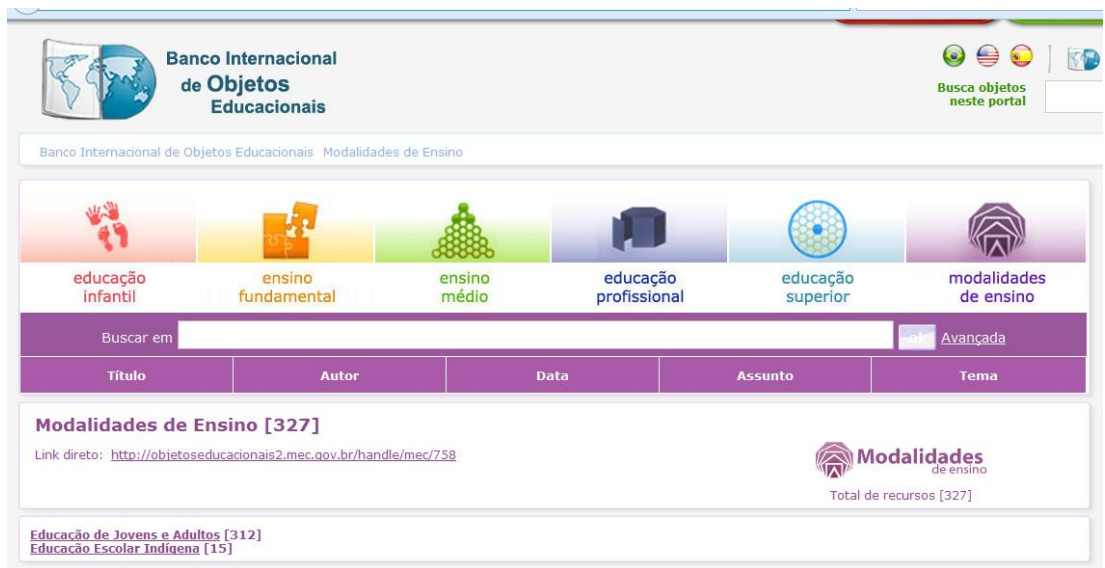

Fonte: BIOE. Acesso em: 06 de Agosto de 2016.

Clicando em Educação de Jovens e Adultos ou direto pelo link http://objetoseducacionais2.mec.gov.br/handle/mec/760/browse?type=title, este por sua vez se encontra subdividido em $1^{\circ}$ Ciclo com um total de 125 objetos e $2^{\circ}$ Ciclo com 187 objetos, como observados na figura 4.

Figura 4. Ciclos da Modalidade de Ensino Disponíveis no BIOE.

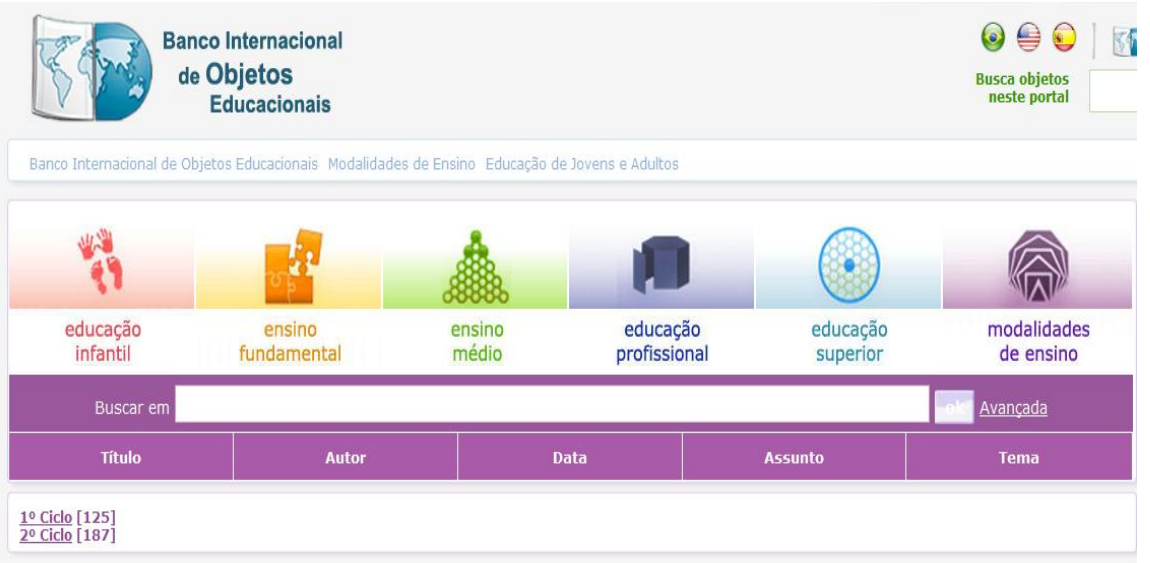

Fonte: BIOE. Acesso em: 06 de Agosto de 2016.

$\begin{array}{llllllll}\text { Ao } & \text { clicamos } & \text { em } & 1^{\circ} & \text { Ciclo } & \text { ou } & \text { através do link }\end{array}$ http://objetoseducacionais2.mec.gov.br/handle/mec/899/browse?type=title, observa-se que esse ciclo esta subdividido em áreas do conhecimento, são elas: Estudo da Sociedade e da Natureza [15], Língua Portuguesa [80] e Matemática [30]. Na área de Sociedade e natureza 
apenas as categorias de áudios [7], Experimentos Práticos [1] e Vídeos [7] apresentam OVAs e desta só a categoria áudio disponibiliza OVAs relacionados à temática da pesquisa como mostra o quadro 1. Já para o segundo $2^{\circ}$ Ciclo da EJA, o BIOE disponibiliza apenas três OVAs na área de geografia, sendo um vídeo e dois áudios.

Quadro 1 - Objetos virtuais de Aprendizagem disponíveis para $1^{\circ}$ Ciclo - Áudios.

\begin{tabular}{|c|l|l|}
\hline Publicação & \multicolumn{1}{|c|}{ Título } & \multicolumn{1}{c|}{ Autores } \\
\hline $20 / 03 / 2008$ & Conhecendo a história do Acre & $\begin{array}{l}\text { Brasil. Ministério da Educação (MEC). Secretaria de } \\
\text { Educação a Distância (SEED) }\end{array}$ \\
\hline $20 / 12 / 2008$ & $\begin{array}{l}\text { Professor meio ambiente parte 01: A } \\
\text { nossa casa }\end{array}$ & $\begin{array}{l}\text { Biblioteca Virtual do Estudante de Língua Portuguesa } \\
\text { (BIBVIRT) }\end{array}$ \\
\hline $04 / 01 / 2009$ & $\begin{array}{l}\text { Professor alfabetizador parte 07: o ser } \\
\text { humano e o meio ambiente }\end{array}$ & $\begin{array}{l}\text { Biblioteca Virtual do Estudante de Língua Portuguesa } \\
\text { (BIBVIRT) }\end{array}$ \\
\hline $30 / 09 / 2010$ & Planárias terrestres? Hein? & Andrade, Cynthia de Paula \\
\hline $02 / 04 / 2013$ & Amazônia & Huth, Hugo; Vilas Boas, Adlane (Coordenação) \\
\hline
\end{tabular}

Fonte: dados da pesquisa.

Considerando o meio ambiente como tema transversal e que a Educação de Jovens e Adultos abordo os conteúdos dos níveis de ensino fundamental e médio, outra forma de verificar objetos disponíveis no Banco Internacional de Objetos Educacionais referente a esta temática para ser trabalhado na EJA é verificar os OVAs disponíveis no BIOE nos níveis fundamental e médio da educação regular.

O nivel Ensino Fudamental pode ser acessado direto pelo Link http://objetoseducacionais2.mec.gov.br/handle/mec/26. Existe para este nível 5068 objetos virtuais de aprendizagem, estes encontram-se divididos em Séries Iniciais com 3440 objetos e Séries Finais, disponibilizando 1628 objetos. Foram analisadas as área do conhecimento que tem relação com tema da pesquisa nas series iniciais e finais.

O quadro 2A mostra a quantidade de objetos apresentados da área do conhecimento Ciências Naturais e Meio Ambiente e o quadro 2B que abordam o tema meio ambiente nas series finais

do ensino fundamental.

Quadro 2A - OVAs disponíveis para Series

Finais do Ensino Fundamental

Área do Conhecimento - Ciências Naturais

\begin{tabular}{|c|c|}
\hline Categorias & Qtde \\
\hline Animações/Simulações & 3 \\
\hline Áudios & 6 \\
\hline Experimentos Práticos & 1 \\
\hline
\end{tabular}

\begin{tabular}{|c|l|}
\hline Hipertextos & 5 \\
\hline Imagens & 0 \\
\hline Mapas & 1 \\
\hline Softwares Educacionais & 6 \\
\hline Vídeos & 0 \\
\hline
\end{tabular}

Fonte: dados da pesquisa. 
Quadro 2B - OVAs disponíveis para Series

Finais do Ensino Fundamental

Área do Conhecimento - Meio Ambiente

\begin{tabular}{|c|c|}
\hline Categorias & Qtde \\
\hline Animações/Simulações & 85 \\
\hline Áudios & 38 \\
\hline
\end{tabular}

\begin{tabular}{|c|c|}
\hline Experimentos Práticos & 6 \\
\hline Hipertextos & 2 \\
\hline Imagens & 471 \\
\hline Mapas & 2 \\
\hline Softwares Educacionais & 14 \\
\hline Vídeos & 247 \\
\hline
\end{tabular}

Fonte: dados da pesquisa.

Os quadros 3A e 3B abaixo mostram as quantidades de objetos apresentados da área do conhecimento Ciências Naturais e Meio Ambiente que abordam o tema meio ambiente nas series Iniciais do ensino fundamental.

Quadro 3A - OVAs disponíveis para Series Iniciais do Ensino Fundamental

\begin{tabular}{|c|c|}
\hline \multicolumn{2}{|c|}{ Área do Conhecimento Ciências Naturais } \\
\hline Categorias & Qtde \\
\hline Animações/Simulações & 14 \\
\hline Áudios & 5 \\
\hline Experimentos Práticos & 0 \\
\hline Hipertextos & 4 \\
\hline Imagens & 0 \\
\hline Mapas & 1 \\
\hline Softwares Educacionais & 2 \\
\hline Vídeos & 11 \\
\hline
\end{tabular}

Fonte: dados da pesquisa.
Quadro 3B - OVAs disponíveis para Series Iniciais do Ensino Fundamental.

\begin{tabular}{|c|c|}
\hline \multicolumn{2}{|c|}{ Área do Conhecimento Meio Ambiente } \\
\hline Categorias & Qtde \\
\hline Animações/Simulações & 52 \\
\hline Áudios & 23 \\
\hline Experimentos Práticos & 2 \\
\hline Hipertextos & 3 \\
\hline Imagens & 98 \\
\hline Mapas & 0 \\
\hline Softwares Educacionais & 8 \\
\hline Vídeos & 67 \\
\hline
\end{tabular}

Fonte: dados da pesquisa.

No BIOE o Ensino Médio dispõe de 10289 objetos. Destes 1590 são na área de Biologia, 216 em geografia e 1723 em Química. Em Biologia apesar do grande números de objetos só apresenta 5 simuladores e 1 software educacional que tratam do tema meio ambiente. Já para Geografia apenas 6 simuladores e 4 áudios. Em Química como nas demais áreas esta subdividida em categorias, a figura 5 abaixo mostra as categorias para a área de química e a quantidade de objetos oferecidos para as mesmas, sendo que das categorias apenas 6 simuladores abordam a temática.

Figura - 5. Objetos para Ensino Médio de Química do BIOE. 


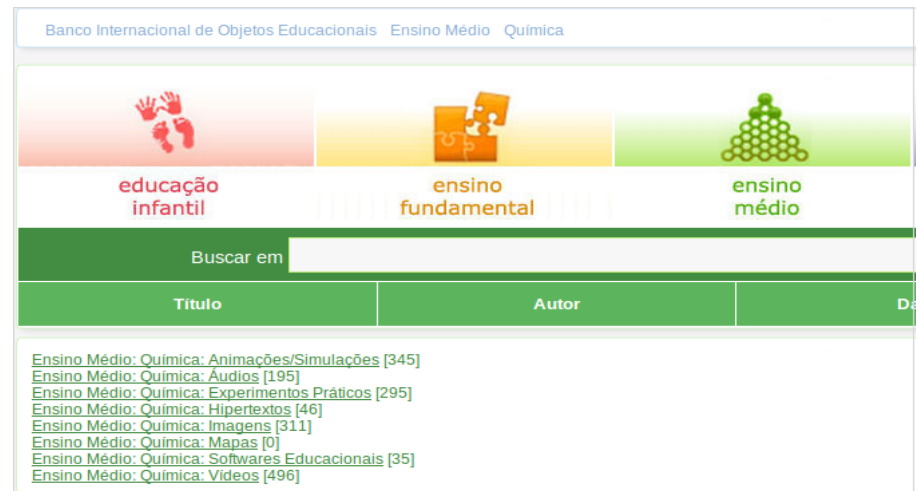

Fonte: BIOE. Acesso em: 11 de novembro de 2016.

Para a Educação Profissional são oferecidos 523 objetos virtuais de aprendizagem, subdividido em áreas do conhecimento, dentre estas áreas temos: Ambiente, Saúde e Segurança disponibilizando 107 objetos e Recursos Naturais com 29 objetos. Clicando em Recurso Naturais e em seguida Animações/Simulações, estes disponibilizam 10 OVAs que trabalham o tema meio ambiente, como se observa no quadro 5. Para a área do conhecimento Ambiente, Saúde e Segurança, esta também dispõe de 10 simuladores dos 25 apresentados que enfocam a temática.

Salienta-se que para as duas áreas são os mesmos simuladores, o que acontece pelo fato de mais ser comum um mesmo objeto desde repositório ser utilizado em mais de um nível de ensino e/ou área de conhecimento e/ou disciplina, principalmente em temas transversais como o tratado nesta pesquisa.

Quadro 5 - OVAs disponíveis para a Educação Profissional que abordam o tema meio ambiente
\begin{tabular}{|l|}
\hline \multicolumn{1}{|c|}{ Animações/Simulações } \\
\hline Mudanças Ambientais Globais \\
\hline Mudanças Ambientais Globais - Abertura \\
\hline Mudanças Ambientais Globais - As Mudanças Climáticas \\
\hline Mudanças Ambientais Globais - Conclusões O que nos Espera no Futuro \\
\hline Mudanças Ambientais Globais - Experiência - Efeito Estufa \\
\hline Mudanças Ambientais Globais - Impacto das Mudanças Climáticas no Brasil \\
\hline Mudanças Ambientais Globais - Mudanças Climáticas Naturais \\
\hline Mudanças Ambientais Globais - O Ciclo do Carbono \\
\hline Mudanças Ambientais Globais - O Ciclo do Nitrogênio \\
\hline Mudanças ambientais globais: o efeito estufa
\end{tabular}

Fonte: dados da pesquisa.

O BIOE constituísse como um repositório, disponibilizando objetos virtuais de aprendizagem que podem auxiliar no processo de ensino aprendizagem, em todos os níveis, 
inclusive na Educação de Jovens e Adultos. Objetos esses são acessados de forma gratuita e podem auxiliar professores e alunos no processo educacional.

\section{CONSIDERAÇÕES FINAIS}

No BIOE estão disponibilizados 19.842 objetos publicados e 174 objetos sendo avaliados ou aguardando autorização para serem publicados. Desses 19.842 objetos, para a Educação de Jovens e Adultos são apresentados 312. O objetivo desta pesquisa, que centra em apresentar aos professores e alunos objetos virtuais de aprendizagem do Banco Internacional de Objetos Educacionais na Educação de Jovens e Adultos com enfoque no tema meio ambiente, para auxiliar no processo de assimilação de conteúdos pelos educandos relacionados a este temática.

A presente pesquisa contribui para que professores e alunos tomem conhecimentos dos objetos virtuais de aprendizagem disponíveis no BIOE e possam utilizá-los como auxilio no processo ensino aprendizagem nas aulas de Ciências, Química, geografia e Biologia na Educação de Jovens e Adultos com foco no tema meio ambiente.

\section{REFERÊNCIAS}

BRASIL. Lei N. 9.795, de 27 de Abril de 1999: Política Nacional de Educação Ambiental. Brasília, 27 de abril de 1999.

BRASIL: Ministério da Educação - Secretaria de Educação Média e Tecnológica.

Parâmetros Curriculares Nacionais para o Ensino Médio. Brasília: MEC/SEMTEC, 1999.

FONSECA, J. J. S. Metodologia da pesquisa científica. Fortaleza: UEC, 2002. Apostila

FREITAS, Andréia Cristina Santos; SANTOS, José Everaldo Oliveira; BARRETO, Luciano Vieira. Educação ambiental no ensino de jovens e adultos. Centro Científico Conhecer ENCICLOPÉDIA BIOSFERA, Goiânia, vol.5, n.8, 2009.

GOVERNO DO ESTADO DE RONDÔNIA. Secretaria de Estado da Educação.Educação de Jovens e Adultos-EJA. Ensino Fundamental e Médio. 2013. Disponível em: <http://www.seduc.ro.gov.br/curriculo/wp-content/uploads/2013/02/EDUCACAO-DEJOVENS-E-ADULTOS-EJA.pdf>. Acesso em: 06 nov. 2016.

OLIVEIRA, Felícia Maria Fernandes de. A importância e as principais dificuldades do uso das tics no ensino de química na visão dos docentes da rede estadual do município de 
Cajazeiras-PB. XII Congresso Internacional de Tecnologia na Educação, 2015. Disponível em: 〈http://www.pe.senac.br/ascom/congresso/ocongresso.asp>. Acesso em: 09 de junho de 2016.

PCN+ Ensino Médio: Orientações Educacionais Complementares aos Parâmetros Curriculares Nacionais: Ciências da Natureza, Matemática e suas Tecnologias. Brasília: MEC/SEMTEC, 2002.

PRODANOV, Cleber Cristiano; FREITAS, Ernani Cesar de. Metodologia do trabalho científico: métodos e técnicas da pesquisa e do trabalho acadêmico. 2 ed. Novo Hamburgo: Feevale, 2013.

SOARES, Leôncio José Gomes. Educação de Jovens e Adultos. Rio de Janeiro: Dp\&a, 2002. $168 \mathrm{p}$.

SOUZA, Marcelo P. de et al. Desenvolvimento e Aplicação de um Software como Ferramenta Motivadora no Processo Ensino-Aprendizagem de Química. Rio de Janeiro: UERJ, 2004. 